\title{
Pengaruh aktivitas fisik terhadap kadar gula darah pada pria dewasa
}

\author{
${ }^{1}$ Matius E. Herwanto \\ ${ }^{2}$ Fransiska Lintong \\ ${ }^{2}$ Jimmy F. Rumampuk
}

\author{
${ }^{1}$ Kandidat Skripsi Fakultas Kedokteran Universitas Sam Ratulangi \\ ${ }^{2}$ Bagian Fisika Fakultas Kedokteran Universitas Sam Ratulangi \\ Email: ekananda_herwanto@yahoo.com
}

\begin{abstract}
Physics in sport is important to know, how to do, limits and how should we exercise with a good way, in order to avoid disturbances in the body. A disorder that occurs normally in the form of muscle pain, joint pain, dizziness and others. Exercise techniques included in the basic lessons in physics, that must be understood by all the people, because the exercise should be a part of life. The aim of this study was to determine whether the effect of running to blood sugar. The design of this research is analytic cross sectional or it is only done once in a certain time. Field research locations located at KONI Ahmad Yani street Manado in North Sulawesi. Samples of the research is determined by simple random sampling that totaling 30 people who are young and who met the inclusion criteria, where the cardio exercise conducted and executed in turn, so the calculation is not in a hurry and with maximum results, the measurement of blood sugar is done by tools name autocheck that has proven and the data is analyzed using the wilcoxon test. The results showed that the value of $\mathrm{p}=0.001$, which means the value is $<0.05$. From the results of the research can be concluded that there is a significant influence due to exercise run on blood sugar in normal men. It is recommended that should be a further studying. Conclusion: Still necessary to do further studying like insulin level to know the influence of exercise.
\end{abstract}

Keywords: blood sugar, exercise

\begin{abstract}
Abstrak: Ilmu Fisika dalam berolahraga sangatlah penting untuk mengetahui cara, batasanbatasan dan bagaimana seharusnya kita berolahraga yang baik, agar terhindar dari gangguan didalam tubuh. Gangguan yang terjadi biasanya berupa nyeri otot, nyeri dipersendian, pusing dan lainnya. Teknik berolahraga termasuk di dalam pelajaran dasar dalam ilmu fisika yang harus di pahami dengan baik oleh semua orang, karena berolahraga sudah seharusnya menjadi bagian dalam hidup. Tujuan dari penelitian ini adalah untuk mengetahui apakah adanya pengaruh dari berlari terhadap gula darah. Rancangan dari penelitian ini yaitu analitik secara potong lintang atau hanya dilakukan sekali dalam waktu tertentu. Lokasi penelitian bertempat di lapangan KONI jalan Ahmad Yani Manado Sulawesi Utara. Sampel dari penelitian ditentukan secara simple random sampling yang berjumlah 30 orang yang masih muda dan memenuhi kriteria inklusi, dimana olahraga berlari yang dilakukan, dilaksanakan secara bergantian agar penghitungan tidak terburu-buru dan hasilnya maksimal. Pengukuran gula darah dilakukan dengan alat autocheck yang sudah terbukti dan data dianalisis dengan wilcoxon test. Hasil penelitian menunjukan bahwa nilai $\mathrm{p}=0,001$ yang artinya nilai tersebut $<$ 0,05 . Dari hasil penelitain ini dapat di simpulkan bahwa terdapat pengaruh yang bermakna akibat aktivitas fisik berlari terhadap gula darah pada pria normal. Simpulan: Masih diperlukan pembelajaran lanjutan seperti tingkat insulin untuk mengetahui pengaruh dari latihan fisik.
\end{abstract}

Kata kunci: gula darah, latihan fisik 
Gula darah adalah bahan bakar karbohidrat utama yang ditemukan di dalam darah, dan bagi banyak organ tubuh, gula darah adalah bahan bakar primer. Pada beberapa daerah didalam tubuh, gula darah langsung digunakan sebagai sumber energi dan pada daerah lainnya gula darah diambil dan disimpan sebagai glikogen. ${ }^{1}$ Kestabilan kadar gula harus tetap di jaga untuk mempertahankan fungsi tubuh untuk bekerja dengan sebaik-baiknya. Ketidakseimbangan kadar gula darah dapat memicu berbagai jenis penyakit yang berbahaya. ${ }^{2}$

Penumpukan kadar gula dalam darah merupakan salah satu penyebab terjadinya penyakit diabetes melitus. Kadar gula darah yang tinggi dan tidak dapat terkontrol dalam jangka waktu yang lama pada penderita diabetes melitus dapat menimbulkan beberapa komplikasi. ${ }^{3}$ Saat ini sudah ada alat yang tersedia dalam beberapa merek, yang dapat digunakan pasien diabetes untuk mengukur kadar gula darah mereka dalam setetes darah dari tusukan di ujung jari. ${ }^{4}$ Pada diabetes melitus, insulin yang tidak terkontrol meningkatkan konsentrasi gula dalam darah dan juga ketidakmampuan tubuh dalam memproduksi insulin memperberat kondisi tersebut, situasi ini dikenal sebagai hiperglikemia, sehingga kadar gula dalam darah yang tinggi tersebut akan mempengaruhi terjadinya kerusakan pada tubuh serta kegagalan berbagai jaringan dan organ.

Menurut

American Diabetes Association bahwa komplikasi diabetes dapat dicegah, ditunda dan diperlambat dengan mengendalikan kadar gula darah. Pengelolaan diabetes yang bertujuan untuk mempertahankan kadar gula darah dalam rentang normal, dapat dilakukan secara nonfarmakologis dan farmakologis. Pengelolaan nonfarmakologis yang sangat berpengaruh adalah latihan fisik, salah satunya adalah dengan berlari. $^{6}$ Pengelolaan diabetes melitus meliputi empat pillar, latihan fisik merupakan salah satu dari ke empat pilar tersebut. ${ }^{7}$

Pada orang non diabetes yang melakukan latihan fisik dengan teratur, memiliki tingkat toleransi insulin terhadap gula darah yang normal atau meningkat. ${ }^{8}$ Anjuran untuk melakukan latihan fisik, bagi para penderita diabetes telah dilakukan sejak seabad yang lalu oleh seorang dokter dari dinasti Sui di China dan kegunaan latihan fisik ini masih terus diteliti hingga kini. ${ }^{7}$ Kesimpulan sementara adalah bahwa latihan fisik secara teratur yang di lakukan oleh penderita diabetes, akan mengurangi risiko terjadinya komplikasi, dan akan meningkatkan tingkat harapan hidup., ${ }^{3,7}$

Subjek dari metabolisme dalam latihan fisik sangat besar, salah satunya berlari sprint atau berlari marathon. Seperti yang diketahui latihan fisik dengan tenaga penuh hanya akan berlangsung dalam waktu singkat, sedangkan dengan tenaga kecil dapat berlangsung lama. Jadi pada latihan fisik tubuh akan membutuhkan energi dengan kata lain dikenal sebagai ATP. ATP yang di perlukan tubuh berasal dari metabolisme gula dalam darah yang akan menghasilkan asam piruvat, asam laktat dan asetilkoenzim A sebagai senyawasenyawa antara. Oleh karena itu, energi untuk sebagian besar fungsi sel dan jaringan berasal dari gula darah. ${ }^{4}$ Simpanan gula darah pada seseorang yang normal tanpa asupan makanan, hanya cukup untuk menunjang untuk berlari dengan kecepatan sedang dan hanya dapat berlari dalam waktu beberapa menit, kemudian pasokan gula darah harus di isi lagi. ${ }^{9}$ Menurut pemaparan diatas, latihan fisik sangat berpengaruh terhadap gula darah, karena hampir seluruh aktivitas di dalam tubuh membutuhkan energi dan energi yang dibutuhkan tersebut berasal dari gula dalam darah yang dapat di peroleh dari asupan makanan sehari-hari, ${ }^{4}$ maka penulis tertarik untuk mengetahui pengaruh aktivitas fisik terhadap kadar ula darah pada pria dewasa.

\section{METODE PENELITIAN}

Metode penelitian ini bersifat survey analitik dengan menggunakan desain potong lintang (Cross Sectional). Data yang di dapat pada saat turun ke lapangan di teliti dan diambil keputusan. Lokasi penelitian di lapangan KONI, jalan Ahmad 
Yani, Sario, Manado. Populasi penelitian adalah Semua pria yang berlari di lapangan KONI, sedangkan sampel penelitian berjumlah 30 orang yang berjenis kelamin laki-laki yang berumur 18-25 tahun, tidak diabetes melitus dan tidak masuk kriteria obesitas. Alat dan bahan yang digunakan adalah lembaran informed consent, alat ukur kadar gula darah, literatur-literatur yang berhubungan dengan karya tulis ilmiah, laptop dan alat tulis menulis. Variabel Penelitian yang diteliti yaitu :

1. Umur

2. Indeks massa tubuh

3. Gula darah

Cara kerja dari penelitian ini yaitu mengukur kadar gula darah sebelum berlari dan kemudian subjek berlari lalu dilakukan pengukuran kadar gula darah setelah berlari. Subjek tidak dalam keadaan berpuasa, jadi yang dipakai adalah gula darah sewaktu. Data diolah dan disajikan dalam bentuk tabel.

\section{HASIL PENELITIAN}

Berdasarkan hasil penelitian yang dilakukan di lapangan KONI manado pada 30 orang subjek, maka ditemukan 25 orang subjek yang memiliki penurunan kadar gula darah dan 5 orang yang memiliki kenaikan kadar gula darah.

Tabel 1 menunjukkan sebanyak 30 subjek penelitian yang terdiri dari 2 subjek yang berumur 18-19 tahun (6,6\%), 25 subjek yang berumur 20-22 tahun (83,5\%), 3 subjek yang berumur 23-25 tahun (9,9\%).

Tabel 1. Distribusi subjek berdasarkan umur

\begin{tabular}{ccc}
\hline & $\mathrm{n}$ & $(\%)$ \\
\hline $18-19$ & 2 & 6,6 \\
$20-22$ & 25 & 83,3 \\
$23-25$ & 3 & 10,0 \\
\hline Total & 30 & 100 \\
\hline
\end{tabular}

Berdasarkan data pada Tabel 2, didapatkan bahwa subjek dengan berat badan normal berjumlah 25 subjek (83,3\%), subjek dengan berat badan rendah berjumlah 3 subjek $(10,0 \%)$ dan subjek dengan berat badan lebih berjumlah 2 subjek (6,6\%).
Tabel 2. Distribusi sampel berdasarkan index massa tubuh

\begin{tabular}{ccc}
\hline & $\mathrm{n}$ & $(\%)$ \\
\hline Normal & 25 & 83,3 \\
Overweitght & 2 & 6,6 \\
Underweight & 3 & 10,0 \\
\hline Total & 30 & 100 \\
\hline
\end{tabular}

Tabel 3 menunjukan karakteristik glukosa darah sampel sebelum dan setelah berlari, dapat dilihat terjadi penurunan glukosa darah pada nilai rata-rata glukosa darah sebelum dan sesudah berlari dengan nilai rata-rata sebelum berjumah 111,40 $\mathrm{mm} / \mathrm{Hg}$ dan nilai rata-rata setelah berlari $96,90 \mathrm{~mm} / \mathrm{Hg}$. Nilai minimum glukosa darah sebelum berlari adalah $76 \mathrm{~mm} / \mathrm{Hg}$ dan setelah berlari $50 \mathrm{~mm} / \mathrm{Hg}$. Glukosa darah sebelum berlari dengan nilai tertinggi adalah $166 \mathrm{~mm} / \mathrm{Hg}$ dan glukosa darah setelah berlari dengan nilai tertinggi adalah $245 \mathrm{~mm} / \mathrm{Hg}$.

Tabel 3. Karakteristik Glukosa darah sampel sebelum dan setelah berlari

\begin{tabular}{ccc}
\hline & GD & \\
& Sebelum & GD Sesudah \\
\hline $\mathrm{N}$ & 40 & 40 \\
Minimum & 76 & 50 \\
Maximum & 166 & 245 \\
Median & 108 & 93,5 \\
Mean & 111,4 & 96,9 \\
Std. Deviation & 21,836 & 32,373 \\
\hline
\end{tabular}

Berdasarkan Tabel 4, menunjukan pengaruh berlari terhadap gula darah seorang pria dewasa normal dimana nilai $\mathrm{P}=0,001<0,05$ sehingga dapat dinyatakan sesuai uji wilcoxon dimana nilai $\alpha=0,05$, data tersebut dinyatakan terjadi perubahan yang signifikan antara gula darah sebelum berlari dengan gula darah setelah berlari.

\section{BAHASAN}

Pada analisis Univariat menunjukan usia terendah adalah usia 18 tahun yang berjumlah satu orang dan usia yang tertinggi adalah 25 tahun, rentan usia yang di pakai tidak terlalu jauh, sehingga dapat memenuhi kriteria dari pengelompokan 
kadar gula darah pada rentan usia pria dewasa.

Tabel 4. Data Hasil Uji Perbedaan GD Sebelum dan GD sesudah

\begin{tabular}{ccc}
\hline $\begin{array}{c}\text { Mean } \\
\text { GD } \\
\text { Sebelum }\end{array}$ & $\begin{array}{c}\text { Mean } \\
\text { GD Sesudah }\end{array}$ & Nilai p \\
\hline 111,40 & 96,90 & $\mathrm{p}=0,001$ \\
\hline
\end{tabular}

Subjek yang dipakai bukanlah seorang atlet yang sering melakukan aktivitas fisik setiap hari, tetapi seorang mahasiswa ataupun simpatisan yang kebetulan berlari di lapangan KONI (Komite Olahraga Nasional Indonesia), dengan berat badan yang tidak tergolong gemuk dan tinggi badan yang sesuai untuk berat badan yang di miliki. Sebelum subjek dimintai untuk berlari, terlebih dahulu dihitung Index massa tubuh dari masing-masing subjek tersebut dan jika didapati tidak ada yang masuk pada kriteria obesitas maka subjek akan di minta untuk mulai berlari secara bergantian agar tidak terjadi kesalahan dalam pemeriksaan kadar gula darah karena terburu-buru. Terdapat dua subjek yang memiliki berat badan lebih tapi belum termasuk ke dalam kriteria obesitas. Jadi, kedua data subjek tersebut akan tetap dipakai. Subjek dengan berat badan yang masuk kriteria obesitas tidak di pakai, karena obesitas mempegaruhi kadar gula darah seseorang dan akan mempengaruhi juga aktivitas fisik tubuhnya, karena pada orang dengan obesitas insulin tidak dapat bekerja maksimal membantu sel-sel tubuh menyerap glukosa karena terganggu oleh komplikasi-komplikasi obesitas, salah satunya adalah kadar lemak darah yang tinggi terutama kolesterol dan trigliserida. ${ }^{10}$

Pada penelitian yang dilakukan pada 30 orang subjek didapati 25 orang yang gula darahnya menurun setelah melakukan aktivitas dalam kata lain berlari dengan kecepatan ringan dalam waktu 15 menit, ada yang kadar gulanya menurun hanya 1 $\mathrm{mg} / \mathrm{dL}$ dan ada juga yang menurun sebanyak $60 \mathrm{mg} / \mathrm{dL}$, sedangkan lima orang subjek memiliki kenaikan gula darah, dimana terdapat subjek yang mengalami kenaikan yang dapat dikatakan cukup tinggi yaitu dari $130 \mathrm{mg} / \mathrm{dL}$ menjadi 245 $\mathrm{mg} / \mathrm{dL}$. Pengambilan data subjek dalam halnya kadar gula darah, dilakukan bukan pada saat berpuasa tetapi pada subjek yang sudah mengkonsumsi makanan selang 1-3 jam sebelum berlari, kenaikan gula darah pada subjek yang berlari selama 15 menit memiliki beberapa penyebab, seperti yang sudah di bahas di bab satu dan bab dua, bahwa gula darah pada beberapa daerah tubuh langsung digunakan sebagai sumber energi tetapi, pada daerah lainnya gula darah diambil dan disimpan sebagai glikogen melalui tahap glikogenesis terutama di dalam organ hati. ${ }^{1}$

Pada saat tubuh membutuhkan energi, glukosa akan diproses untuk menghasilkan energi melalui tahapan glikolisis, dekarboksilasi oksidatif, siklus krebs, dan transfer elektron. Tahapan tersebut dapat terjadi apabila terdapat oksigen dalam jaringan sehingga prosesnya disebut respirasi aerob (menghasilkan energi dengan adanya oksigen). ${ }^{11,12}$ Ketika gula darah yang beredar tidak mencukupi untuk memenuhi kebutuhan energi yang diperlukan secara mendadak seperti berjalan atau berlari, maka glikogen yang adalah simpanan energi cadangan di dalam hati diubah menjadi glukosa melalui tahap glikogenolisis dan dilepaskan ke dalam darah untuk menghasilkan energi dalam jumlah yang besar untuk memenuhi kebutuhan energi tubuh. ${ }^{13}$

Pada masing-masing individu terjadinya proses glikogenolisis tergantung pada kebutuhan energi dalam tubuh, sehingga ada yang terjadi secara cepat, bertahap dan ada yang lama. Hal ini, dikarenakan oleh dua hal yang pertama adalah waktu terakhir subjek mengkonsumsi makanan dan yang kedua adalah kebiasaan beraktivitas dari subjek tersebut, jika subjek sering melakukan aktivitas fisik maka penggunaan energi akan semakin sedikit dikarenakan tubuh telah terbiasa dengan aktivitas fisik. Oleh karena itu, dalam penelitian kali ini, dapat menjelaskan kenapa ada subjek yang 
memiliki kadar gula darah yang meningkat, dikarenakan proses glikogenolisis yang berlangsung lebih lama dibanding yang lainnya. Sehingga pada saat dilakukan pemeriksaan gula darah, didapati ada subjek yang gula darahnya meningkat dibandingkan dengan sebelum berlari karena pada saat pengecekan kadar gula darah, proses glikogenolisis masih sementara berlangsung, sehingga kadar gula darah yang beredar di darah lebih banyak dibandingkan dengan kadar gula darah sebelum berlari.

Banyak alternatif lain yang dapat dilakukan untuk berolahraga seperti bersepeda, berenang dan senam. Semua cara tersebut dapat menurunkan kadar gula darah, tergantung dari intensitas latihan itu sendiri. Pada penelitian ini seperti pada tabel tiga, didapatkan penurunan gula darah yang sangat berarti setelah berlari, jika dilihat pula dari nilai rata-rata gula darah sebelum $=111,4$ dan nilai sesudah berlari $=$ 96,9, di dapatkan bahwa terjadi penurunan tingkat gula darah pada subjek sebelum dan sesudah berlari. Jadi, berdasarkan hasil pada penelitian ini didapatkan ada pengaruh yang bermakna dari berlari terhadap gula darah pada pria dewasa, karena pada uji Wilcoxon test didapati nilai $\mathrm{p}=0,001(<0,05)$. Oleh karena itu, dapat dinyatakan bahwa memang beraktivitas fisik berlari, akan sangat berpengaruh terhadap gula darah pada pria dewasa seperti yang di teliti. Jadi berlari dapat digunakan untuk menjaga kadar gula darah dalam keadaan normal jikalau dilakukan dengan teratur dan dalam batas kemampuan dari seseorang itu sendiri, berolahraga juga dapat mempertahankan kadar gula darah agar tetap normal, pada seseorang sudah memiliki riwayat gula darah yang tinggi.

\section{SIMPULAN}

Berdasarkan hasil yang dilakukan di lapangan KONI Manado pada 30 orang subjek yang berlari periode Oktober November 2015 mengenai kadar gula darah subjek sebelum berlari dan setelah berlari, dapat disimpulkan bahwa:

1. Terdapat perbedaan antara gula darah sebelum berlari dan setelah berlari, sebanyak 25 orang mengalami penurunan gula darah dan sebanyak 5 orang mengalami kenaikan kadar gula darah.

2. Pengujian dengan wilcoxon test didapatkan perubahan yang signifikan, sehingga dapat dikatakan terjadi pengaruh aktivitas fisik berlari terhadap kadar gula darah pada pria dewasa normal.

\section{SARAN}

Berdasarkan hasil penelitian, pembahasan dan kesimpulan, maka penulis menyarankan:

1. Penelitian lanjutan dibutuhkan pada rentan usia di atas 25 tahun dengan cara dan sarana yang berbeda.

2. Penelitian dengan variabel berbeda seperti kadar insulin pada pria sangat dibutuhkan sehingga dapat lebih memperjelas pengaruh penurunan kadar gula darah.

3. Aktivitas fisik berlari dapat diterapkan bagi para penderita diabetes, sehingga kadar gula darah dapat dikontrol dan tidak menimbulkan komplikasi yang berbahaya.

\section{DAFTAR PUSTAKA}

1. Fried G, Hademenos G. Schaum's Outlines : Biologi. Bab 15, Homeostasis: Regulasi fungsi-fungsi fisiologis. Edisi 2. 2005; p.177.

2. Permana H. Terapi Cairan dan Nutrisi Pada Kelainan Endokrinologi. Sub bagian Endokrinologi dan metabolisme, Fakultas Kedokteran Universitas Padjadjaran (Tesis). 2009. Diambil dari : http://pustaka.unpad.ac.id/wpcontent/uploads/2009/09/terapi_caira n_dan_nutrisi_pada_kelainan_endokr inologi.pdf . Diakses 20 januari 2016.

3. International Diabetes Federation. IDF Diabetes Atlas. Six edition. 2013; Tersedia dari: www.idf.org/aboutdiabetes. Diakses 19 september 2015.

4. Sacher R, McPherson R. Kimia Umum. Tinjauan Klinis Hasil Pemeriksaan Laboratorium, Edisi 11. EGC. 2004; 
p.287-9.

5. Newsholme E, Leech A. Biochemistry for the Medical Sciences. 1994; h.347361.

6. Medicastore. Diabetes, Sillent Killer. Diambil dari http://medicastore.com/diabetes/diabe tes_mellitus.php, 2007. Diakses 20 september 2015.

7. Sudoyo A, Setiyohadi B, Alwi I, Simadibrata M, Setiadi S. Latihan Jasmani. Buku Ajar Ilmu Penyakit Dalam Jillid III, Edisi 5. 2009; h.1893-5.

8. Ardinata A. Perbandingan Hasil Uji Toleransi Glukosa Oral Pada Pria Terlatih Dengan Tidak Terlatih (Tesis). Universitas Sumatera Utara; 2002.

9. Dawn M, Allan M, Collen S. Biokimia Kedokteran

Dasar, Sebuah
Pendekatan Klinis, EGC. 2000; p.270- 473.

10.Diabetes dan Obesitas. Tersedia dari : http://olvista.com/kesehatan/diabetesdan-obesitas-kegemukan/ . 2011. Diakses 14 Januari 2016.

11.Proses dan Tahapan Glikolisis. Tersedia dari http://www.edubio.info/2015/08/pros es-dan-tahapan-glikolisis.html. 2015. Diakses 14 Januari 2016.

12.Murray $R$, Granner $D$, Rodwell $V$. Biokimia Harper, Bab 2, Glikolisis dan Oksidasi Piruvat, Edisi 27. 2009; p.158-9.

13.Perbedaan antara Glikogen dan Glukosa. Tersedia dari : http://www.sridianti.com/perbedaanantara-glikogen-danglukosa.html.2015. Diakses Januari 2016. 